\title{
Special Sessions Description: Advancing the Cause of Cause-Related Marketing
}

\author{
Josh Coleman, Katharine Howie, Parker Woodroof, and Rebecca VanMeter
}

\begin{abstract}
Today, many companies have the resources and expertise to make meaningful contributions to worthy causes. They also possess the visibility and advertising wherewithal to lend credibility to these causes and generate awareness for pressing social issues. This special session highlights the evolution, current development, and potential changes in the world of cause-related marketing (CRM) since its inception in 1983 by the American Express. Moreover, although countless campaigns have generated successful outcomes for various stakeholders of the firm, CRM is far from a foolproof marketing communication tool. This panel presents its own primary research findings focused on how companies, consumers, and nonprofits are affected by this type of corporate social responsibility. This session also illuminates some of the challenges and shortcomings that currently exist within a CRM context. For example, although many companies are drawn to social sponsorship that is easily marketable (e.g., helping sick children), still, less marketable important social issues are left unaddressed (e.g., needs of the homeless). Our intention is not only to celebrate the successes of CRM but also develop an agenda for future research to combat the current weaknesses to ensure the health and longevity of this valuable marketing tool.
\end{abstract}

\footnotetext{
J. Coleman $•$ P. Woodroof

University of Memphis, Memphis, TN 38152, USA

e-mail: jtcleman@memphis.edu; parkerwoodroof@gmail.com

K. Howie $(\varangle)$

The University of Mississippi, Oxford, MS 38677, USA

e-mail: kgriffi1@go.olemiss.edu

R. VanMeter

Ball State University, Muncie, IN 47306, USA

e-mail: vanmeter@bsu.edu
} 